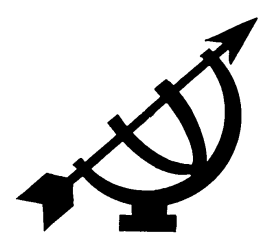

\title{
Musiek as heelbreinaktiwiteit by innerlike verandering
}

\author{
J.R. Elyon \& G.A. Lotter \\ Vakgroep Praktiese Teologie \\ Potchefstroomkampus \\ Noordwes-Universiteit \\ POTCHEFSTROOM \\ E-pos: elyonblessing@gmail.com \\ George.lotter@nwu.ac.za
}

\begin{abstract}
The role of music as wholebrain activity in inner change

In this article the importance of music as wholebrain activity in the context of inner change is discussed. Attention is given to the following relevant features: the psychological dimensions, the postmodern context in which it happens, functions of the brain and especially the consequences of the use of the whole brain instead of the leftbrain approach. The background to the development of music and the influence it may have on inner change is also discussed. Due to the paradigm shift towards postmodernity, feelings and experiences are more easily expressed. According to the results of the research inner change and healing of the postmodern individual may be promoted by the use of music as well as symbols, metaphors, rituals and art. The final conclusion of this article is that music as a wholebrain activity can and should be used to bring about inner change.
\end{abstract}

\section{Opsomming}

Die rol van musiek as heelbreinaktiwiteit by innerlike verandering

In hierdie artikel word die belangrikheid van musiek as heelbreinaktiwiteit vir innerlike verandering aangetoon. Daar word aandag gegee aan die relevante aspekte daarvan: die psigologiese dimensies, die postmoderne konteks waarbinne dit gebeur, die funksie van die brein en veral die belang van die gebruik van die hele brein teenoor die linkerbreinbenadering. Verder word die agtergrond van musiek en die invloed daarvan op innerlike verandering bespreek. As gevolg van die paradig- 
maskuif na die postmodernisme word gevoelens en ervarings makliker uitgedruk. Volgens die bevindings van hierdie artikel word innerlike verandering en heelwording van die postmoderne mens moontlik deur die gebruik van musiek en die aanwending van simbole, metafore, rituele en die kunste. Die finale gevolgtrekking waartoe gekom is, is dat musiek as heelbreinaktiwiteit gebruik kan en behoort te word om innerlike verandering teweeg te bring.

\section{Inleiding}

Hulpverlening met betrekking tot innerlike verandering is in die verlede hoofsaaklik vanuit die werking van die linkerhemisfeer van die brein benader (Janse van Rensburg, 1998:65). Dit beteken byvoorbeeld dat pastorale bystand in die verlede hoofsaaklik onder die invloed van die modernisme op 'n intellektueel-analitiese vlak verleen is. Dit het neergekom op ' $n$ verenging en beperking van die moontlikhede wat gebruik kan word wanneer innerlike verandering beoog word. Vir enige terapeutiese aktiwiteit en beradingshulp is innerlike verandering die ideaal waarna gestreef word.

Vir innerlike verandering om waarlik effektief te wees, behoort dit die mens in sy totaliteit te omvat. Maritz en Dreyer (2001:1270) het daarom aangetoon dat ' $n$ aantal nuwe sienings 'n invloed uitoefen op die huidige perspektiewe waar innerlike verandering ter sprake is in byvoorbeeld die pastoraat as wetenskap. Die belangrikste daarvan is dat geloof nie slegs feitelike kennis van die Woord is nie, maar ook die ervaring daarvan. Slegs wanneer die Skrif eerstehands ervaar word, word die gelowige mens in sy geheel aangeraak. Clinebell (1984:27) het reeds meer as twintig jaar gelede aangetoon dat pastorale terapeute regterbreinaktiwiteit by die bestaande linkerbreinaktiwiteit moet integreer indien hulle die hele mens effektief wil bereik om sodoende innerlike verandering teweeg te bring.

Die probleemstelling wat in hierdie artikel ondersoek word, is hoe musiek as heelbreinaktiwiteit vir pastorale terapie aangewend kan word met die oog op innerlike verandering.

Die doel van hierdie artikel is om sekere perspektiewe en gepaardgaande paradigmaskuiwe wat plaasgevind het en steeds plaasvind met betrekking tot die rol van musiek by innerlike verandering te ondersoek en om die belangrikheid van die rol van musiek as heelbreinaktiwiteit by innerlike verandering aan te toon. 


\section{Verandering}

Fasilitering van verandering in die lewens van kliënte/beradenes is die gemeenskaplike doelwit van alle terapie en berading (Corey, 2001:17; vgl. Louw, 2000:366). Dit lei tot die vrae of mense kan verander en hoe hulle verander? Is dit eksterne faktore wat tot verandering lei of kom verandering van binne?

Verandering lok twee verskillende reaksies by mense uit. Sekere mense sien verandering as bedreigend, terwyl ander dit as 'n geleentheid sien om aan te gryp (Schmidt, 1997:88). Omdat die meeste mense van die bekende hou en lief is vir roetine, bied hulle gewoonlik weerstand teen verandering. Alhoewel verandering dikwels lonend is, veral wanneer dit resultate oplewer, voel dit soms asof die bestuur daarvan nie haalbaar is nie (Welch \& Welch, 2005:133-134; vgl. ook Jaffe \& Scott, 1999:8).

Psigoterapie kan slegs in sekere gevalle die veranderingsproses in beweging bring en kan ook nie waarborg dat die verandering altyd gaan intree nie. Die individu moet erken dat daar 'n sekere area in sy lewe is wat regstelling of aanpassing benodig. Erkenning is 'n kritieke deel van verandering. Dit is die begin van verandering en impliseer dat verandering moontlik is (Welch, 1998:27). Vir verandering om suksesvol en blywend te wees, is dit van kardinale belang om verandering te versterk (reinforce) sodra dit intree (Andreas \& Faulkner, 1998:22).

\subsection{Psigologiese perspektiewe op verandering}

Engler (1991:23) onderskei drie hoofdoelwitte in psigoterapie, naamlik:

- Die verstaan van die self en die menslike natuur. 'n Voorbeeld hiervan is Psigoanalise.

- Etiese doelwit: Terapie moet as diensbaar aan die kliënt se verandering en groei gesien word, asook om 'n beter lewensgehalte te handhaaf. ' $n$ Voorbeeld hiervan is die persoon-gesentreerde terapie van Rogers, omdat dit klem plaas op die gesindheid wat die terapeut skep om verandering in die kliënt te fasiliteer.

- Kuratiewe doelwit: fokus op die vervanging van problematiese simptome met meer gepaste gedrag. 'n Gepaste voorbeeld hiervan is die gedragsterapeut wat hom/haar verantwoordelik ag vir die fasilitering van verandering. 


\subsubsection{Die Freudiaanse benadering: psigoanalise}

Psigoterapie is deur Sigmund Freud (1856-1939) ontwikkel. As 'n terapeutiese toepassing van die wetenskap van die menslike denke het Freud psigoanalise die lig laat sien. As 'n neuroloog wat later 'n psigiater geword het, was Freud veral geïnteresseerd in die biologiese basis van die geesteslewe van die mens (vgl. Smith, 1996:19).

Wolitzky (1995:38) is oortuig dat daar geen enkele faktor in die benadering van Freud is wat as ' $n$ element van verandering beskou kan word nie. Verhouding en insig wat op interpretasie gebaseer is, is vir Freud die twee hoofkategorieë in die kuratiewe faktor van behandeling.

Enigiets wat die intrapsigiese balans van persoonlikheid versteur/ ontstel, kan volgens die Freudiaanse teorie tot die proses van verandering bydra (Smith, 1996:26). Die fundamentele teorie van verandering is volgens Bertram en Widener (1995:41) dat die onbewuste nie verander kan word nie - slegs die bewuste (vgl. Karasu, 2005:2485).

\subsubsection{Rasioneel-emotiewe gedragsterapie en verandering}

Die einddoel van gedragsterapie is om die lewensgehalte van pasiënte te bevorder deur hulle gedrag te verander en sodoende disfunksie in hulle lewe te verminder (Jacob \& Pelham, 2005:2498). Volgens Macaskill (1990:20) is dit uiters moeilik om mense se oortuigings (geloof) te verander en hy is van mening dat dit harde werk en deursettingsvermoë verg om mense se oortuigings te verander, omdat mense soms onrealistiese verwagtings oor die verandering van hulle irrasionele oortuigings (geloof) koester.

Filosofiese verandering vind plaas wanneer 'n beradene intellektueel bewus is van sy probleem en ook die bron daarvan verstaan (Ellis, 1990:137). Volgens Ellis (1990:137) bring hierdie tipe verandering slegs minimale persoonlikheidsverandering mee. Wanneer 'n beradene aan die ander kant emosionele insig in sy probleem het, sal die verandering meer blywend wees en meer betekenis inhou. Intellektuele bewussyn en emosionele insig help die beradene om verantwoordelikheid vir sy disfunksionele gedrag te aanvaar. Verandering van versteurde gevoelens en gedrag neem 'n aanvang sodra die beradene erken dat hy iets kan doen om sy irrasionele oortuigings (geloof) te verander (vgl. ook Yates, 2003:33; Ellis, 1990: 137). 


\subsubsection{Die humanistiese perspektief}

Sekere psigoloë is daarvan oortuig dat gedragsterapie en psigoanalise nagelaat het om belangrike aspekte van die menslike ervaring onder die loep te neem (McLeod, 1996:133). Dit het gelei tot die humanistiese paradigma. Rogers word hierna bespreek as een van die groot eksponente van die hierdie rigting. Die nuutste ontwikkeling binne hierdie perspektief word genoem psigofortologie (positive psychology) (Peterson, 2006:15).

Sentrale temas van die humanistiese paradigma kan soos volg saamgevat word:

- Hierdie paradigma het psigologie en ander terreine (literatuur, filosofie) van die humanisme geïnkorporeer.

- Dit konsentreer eerder op optimale funksionering as op patologie.

- Dit plaas geweldig baie klem op die individu.

- Dit steun op die wisselwerking in 'n netwerk idees in teenstelling met 'n enkele teoretiese fokus.

\subsubsection{Rogeriaanse benadering: kliënt-gesentreerde terapie}

Carl Rogers is bekend vir sy humanisme asook die benadering in berading wat sy naam dra (vgl. West \& Saunders, 2006:718). Hy openbaar 'n opregte respek vir die individu. As terapeut het hy alles in sy vermoë gedoen om empatie teenoor en ondersteuning van die beradene te toon (Rennie, 1998:iv).

\subsubsection{Rogeriaanse perspektief met betrekking tot verandering}

Volgens McLeod (1996:136) is verandering en verbetering van die persoonlikheid inherent aan menslike ervaring. Die terapeut sal dus nie verandering inisieer nie, maar slegs as 'n fasiliteerder van verandering in die lewe van die kliënt optree. Die terapeut sal dus op die innerlike of eksterne bronne konsentreer wat die verandering in die lewe van die kliënt verhinder.

'n Negatiewe selfkonsep bevorder nie positiewe verandering nie (Thorne, 1996:129). Positiewe verandering word geïnisieer deur sowel die terapeut as die tipe verhouding wat die terapeut met die kliënt het. Effektiewe, betekenisvolle terapie beweeg die kliënt uit 'n posisie van 'n swak, negatiewe selfkonsep na 'n posisie van 'n positiewe selfkonsep. Die kliënt se groei en ontwikkeling van 'n meer 
positiewe selfkonsep sal 'n verbetering in sy/haar gedrag tot gevolg hê (Thorne, 1996:129).

\section{Die invloed van die postmoderne era op die navorsing oor innerlike verandering}

In teologiese en filosofiese kringe is eenstemmigheid dat die mens sigself in die postmoderne era bevind (Kingma \& Lotter, 2002:312; vgl. Van Wyk, 2001:144). Elyon (2005:48) wys daarop dat namate tye verander, die mens se behoefte en nood ook verander. In dieselfde trant skryf Howard Clinebell (1984:16) reeds 24 jaar gelede:

In each period of history and every new environment, the church must find fresh ways of meeting the needs of troubled persons - new channels for its century - spanning the ministry of caring, healing, and growth. Only thus can it remain relevant to the deep needs of people.

Die postmoderne era stel ook nuwe uitdagings aan die pastorale berader/terapeut, omdat die behoefte van die postmoderne mens ook anders daar uitsien (Olthuis, 1999:144).

Voordat postmodernisme deeglik bestudeer en verstaan kan word, is dit noodsaaklik dat modernisme eers onder die vergrootglas geplaas moet word. Descartes word algemeen aanvaar as die "ikoon" van die moderne era, omdat hy die kognitiewe, die logiese funksionering van dinge beklemtoon met sy uitspraak, "omdat ek dink, daarom is ek" (Botha, 2000:26). Die moderne era word gekenmerk deur ekonomiese en tegnologiese welvaart en vooruitgang (Thompson \& Lotter, 2001:187). Die menslike rede is nog 'n prominente kenmerk van die moderne era (Smit, 2007:251). Volgens Steenkamp (1996:752) het die moderne mens sy verwagting en geloof in redding in sy vermoë om te kan redeneer, geplaas. (vgl. Van der Walt, 2006:32; Steyn, 2005:47). Geloof in die mens se potensiaal om goed te wees, sy vermoë om evolusionêr te ontwikkel en utopia op die aarde te skep is fondamente waarop die modernisme gebou is. Hierdie oorskatte geloof en verwagting in die mens se rede en kognitiewe vermoë het 'n radikale invloed op die verhouding van die mens met die self, die ander, die natuur en God tot gevolg gehad. Hierdie mensbeeld het byvoorbeeld meegebring dat die metafisiese en estetiese op die agtergrond geskuif is om plek te maak vir die rasionele magsbeheptheid van die subjek. Maritz en Dreyer (2001: 1267 ) wys daarop dat kuns en musiek ook aan die rede ondergeskik gestel is. 
Nog terme wat die modernistiese paradigma weerspieël, is Newtoniaanse fisika, kognitiewe positivisme, empirisisme, lineêre oorsprong en gevolg, en objektivisme in die meting van aspekte in die natuur (Dixon, 1998:79; vgl. ook Strauss, 2004:260). Vir Thompson (1999:11) is moderniteit 'n progressiewe gebeurtenis wat opgebou het totdat dit in die sewentiende eeu sy hoogtepunt bereik en uitgespoel het. Realisering van persoonlike vryheid en welvaart is voordele wat hierdie verandering teweeg gebring het. 'n Onwrikbare geloof in vooruitgang en die moontlikheid van 'n oplossing van alle probleme was die gevolg van die sogenoemde persoonlike vryheid en welvaart (Steyn, 2005:48). Thompson (1999:11) is ook van mening dat die modernisme nadele inhou. Uitbuiting, verdrukking, morele verval en verwoesting van die omgewing is nadele wat die modernisme veral in die twintigste eeu tot gevolg gehad het.

Gebeurtenisse soos mikro- en makro-ontwikkeling is hoogtepunte wat in die moderne era uitstaan. Die modernisme verwys na die verligte era wat geloof stel in vooruitgang, optimisme en rasionaliteit. 'n Verdere kenmerk van die moderne of verligte era is die soeke na absolute kennis in die tegnologie, die wetenskap en die samelewing (Thompson \& Lotter, 2001:187). Die modernistiese uitgangspunt is dat die soeke na kennis en geloof in die vooruitgang van wetenskaplike en tegnologiese metodes die enigste manier is waarop orde, sekuriteit en geluk in die wêreld verwesenlik kan word (Steyn, 2005:49; vgl. ook Steenkamp, 2002:44-45; Janse van Rensburg, 2000:5-6; Van Huyssteen, 1996:105).

Alhoewel dit moeilik is om postmodernisme te definieer, onderskei sekere begrippe, name en elemente dit van die modernisme (vgl. Smit, 2007:251; Smith, 2006:19; Steyn, 2005:50; Du Toit \& Spangenberg, 2002:1135). Die name en begrippe wat onlosmaaklik aan postmodernisme verbind is, is onder andere die volgende:

- Jaques Derrida - There is nothing outside the text, différence \& différance. (Smith, 2006:31-58; vgl. ook Cahoone, 2003:225240).

- Jean-Francois Lyotard - Incredulity toward metanarratives (Smith, 2006:59-79; vgl. Cahoone:2003:259-273).

- Michel Foucault - Power is knowledge (Smith, 2006:81-107; vgl. ook Cahoone, 2003:250-251).

Olthuis (1999:144) het 'n volledige lys van antiteses opgestel om aan te dui hoe postmodernisme teenoor modernisme gereageer het en hierin is die kontras baie duidelik te sien. Slegs enkele relevante 
aspekte wat betrekking het op die fokus van die artikel, word hieronder in Engels aangehaal:

\section{Modernism}

Confidence in reason (and science) as the way to truth and happiness

\section{modernism privileges}

"the real is logical"

wholes

stability

safety

power-over

genderness (read: male)

equality

center

mind

rational

predictability

what we know

what is seen

faith is illogical

master story

truth

\section{Postmodernism}

Distrust in reason (and science) as the way to truth and happiness

in reaction to resulting imbalances, postmodernism emphasises

"life is more than logic"
fragments
change
risk
power-with
gendered
uniqueness
margins
body
emotional
unpredictability / surprise
what is unknown
what is unseen
faith goes beyond knowledge
stories
truths

Vanuit die seleksie van bogenoemde lys is dit duidelik dat postmodernisme die ideale, idees, gesindhede en die waardes van modernisme deurgaans bevraagteken.

Volgens die postmodernistiese paradigma is daar nie slegs een fundamentele dissipline, of slegs een metodologie vir wetenskappe en slegs een stel beginsels wat vir die mens geld nie (Du Toit \& Spangenberg, 2002:1135). Irrasionaliteit en waarskynlikheid is grondbegrippe waarmee die postmoderniste werk. Volgens die postmoderniste bestaan daar geen absolute of volledige kennis nie. Kennis en verstaan is vir hulle altyd subjektief en konteksgebonde (Van Huysteen, 1996:105; vgl. ook Janse van Rensburg, 2000:5-6). Ook volgens Dreyer (1998:10) word die klem op die magsvrye verband tussen subjek en subjek geplaas. Ontologies bestaan "die waarheid" ook nie; dus het die pastorale berader/terapeut nie "die antwoord" vir 
die beradene nie (vgl. Wilson, 2006:750-752; Dill \& Kotzé 1997:2022; Kotzé \& Kotzé, 1997:35-38). Die vraag kan natuurlik gestel word of daar op so 'n manier na die waarheid verwys kan word. Die bestaan van absolute gesag in die heelal word verwerp (Smit, 2007:252). Om te begryp eerder as om te ken, is die oproep van postmoderne hermeneutiek. Volgens die postmodernistiese opvatting het die pastorale berader/terapeut nie die antwoord vir die beradene nie, maar moet hy/sy (pastorale berader/terapeut) slegs fasiliterend in samewerking met die beradene na 'n geskikte oplossing vir sy probleem soek. Die uiting van multidimensionele denke, gevoelens en ervarings is moontlik gemaak deur die postmoderne paradigmaskuiwe. Daar is weer aandag aan die mens as emosionele wese gegee wat ook nie-rasioneel kan ervaar. As gevolg daarvan is opnuut klem gelê op die invloed wat waardes, simbole, metafore en rituele op die mens uitoefen (Steenkamp, 1996:755). Die postmoderne mens het 'n behoefte aan en honger na geïntegreerdheid en heelheid. Die postmoderne mens se heelwording kan geskied deur die aanwending van simbole, metafore, rituele, musiek en kuns. Volgens Wilson-Dickson (1997:13) is die gesindhede in die Weste besig om te verander. Selfs sielkundiges en psigiaters met hulle wetenskaplike vereistes of objektiewe observasie is bereid om te erken dat geestelike bewustheid en die toepassing van kunsmetodes 'n betekenisvolle bydrae kan lewer tot die geesteswelsyn (mental well-being) van die mens.

Dit kan uit 'n reformatoriese vertrekpunt problematies wees om die waarheid so te relativeer soos dit binne die postmodernistiese paradigma gebeur. Daarom is dit van kardinale belang om hier daarop te wys dat die outeurs hulle nie binne een van bogenoemde paradigmas posisioneer nie, maar wel die postmodernistiese perspektiewe kies wat met die Bybelse beginsels versoenbaar is. Daar is wel instemming met die postmoderne paradigma dat die postmoderne mens behoefte aan geïntegreerdheid en heelheid het, omdat die hele mens in die Bybel ook beklemtoon word (Campbell-Lane, 2003:22; vgl. 1 Tess. 5:23). Die beklemtoning van die effek van waardes, simbole, rituele, metafore en kuns (musiek) op die mens sluit ook aan by die uitgangspunte wat die navorsers huldig oor aspekte wat innerlike verandering bevorder (vgl. Cilliers, 1998:9697). Die vooronderstellings van die navorsers dat die berader/ terapeut uit hom-/haarself nie die antwoord vir die beradene het nie, maar in samewerking met hom/haar fasiliterend na die oplossing moet soek, is ook ' $n$ postmodernistiese perspektief wat met die nodige kwalifikasie aanvaar kan word, omdat dit by die leer van Jesus in Johannes 15 aansluit. Die boodskap van Jesus Christus in 
Johannes $15: 1-8$ is dat ons nie vrugte kan dra as ons nie in Hom bly nie. Die berader/terapeut soek dus biddend die oplossing saam met die beradene by Jesus Christus.

As ' $n$ voorlopige gevolgtrekking van wat bespreek is, kan aangetoon word dat musiek as 'n heelbreinaktiwiteit derhalwe die geskikte medium is en binne die eklekties gekose postmoderne sienings pas, omdat dit gelyktydig op die affektiewe, die kognitiewe en die konatiewe vlak tot die mens spreek.

\section{Musiek as heelbreinaktiwiteit}

\subsection{Breinfunksies}

Ontwikkeling in die navorsing van die brein en funksies van die twee hemisfere van die brein wat deur die corpus callosum aan mekaar verbind is, is bekend (vgl. Voges, 1999:37 en Campbell-Lane, 2003:120).

Die neurochirurg Roger Sperry, 'n spesialis op die gebied van die gesplete brein, is bekend vir die gespletebreinteorie wat hy ontwikkel het (vgl. Strong, 2001:11; Neethling \& Rutherford, 2001:41). Die bevinding van die gespletebreinteorie is dat die een kant van die mens se brein meer aktief as die ander kant is, omdat die mens (beraders én terapeute) die een helfte meer as die ander gebruik (Neethling \& Rutherford, 2001:46; vgl. ook Campbell-Lane, 2003: 120). Voges (1999:30) praat van 'n leidende hemisfeer wanneer sy na bogenoemde verskynsel verwys (vgl. ook Springer \& Deutsch, 1998:12). Daar word na bogenoemde verskynsel verwys as die hemisferiese dominansie (vgl. Campbell-Lane, 2003:120; De Boer et al., 2001:187; Voges, 1999:33; Springer \& Deutsch, 1998:14).

D'Aquili and Newberg (1999:28) wys daarop dat die hemisferiese dominansie bepaal word op grond van die funksies wat in die verskillende hemisfere verrig word en dat die linkerhemisfeer die dominante hemisfeer is vanweë sy taalkapasiteit, analitiese en wiskundige kapasiteite en prosesse, terwyl die regterhemisfeer bekend staan as die nie-dominante hemisfeer waar die nie-verbale bewustheid van die omgewing, ekspressies, persepsies asook die regulering van emosies gevestig is.

Groenewald (2003:17) toon in haar doktorale studie dat beter resultate opgelewer word wanneer albei hemisfere van die brein by die leerproses benut word (vgl. De Boer et al., 2001:187; Wilson, 2000:1; Campbell, 1997:16). Die rede hiervoor is waarskynlik dat 
elke hemisfeer wat sy funksie betref gespesialiseerd is (Voges, 1999:30), maar mekaar tog komplementeer (vgl. De Boer et al., 2001:186; Herrmann, 1996:42; D' Aquili \& Newberg, 1999:28 en Laccino, 1993:29).

Herrmann onderskei vier kwadrante in sy heelbreinmodel (De Boer et al., 2001:186). De Boer et al. wys verder daarop dat die vier kwadrante in bogenoemde model die vier strukture in die dinkfunksie van die brein verteenwoordig. Dit is belangrik om ook te meld dat in die verdeling van die vier kwadrante, die linker- en regterhemisfere die serebrale prosesse verteenwoordig, terwyl die twee halwes (bo en onder) eerder die gevoelsgebaseerde prosesse verteenwoordig (vgl. D'Aquili \& Newberg, 1999:31). Herrmann se model word in Figuur 5 (De Boer et al., 2001:186) opgesom.

Figuur 1: Die Herrmann Heelbreinmodel (Herrman, 1995:411; 1995:30; 1998)

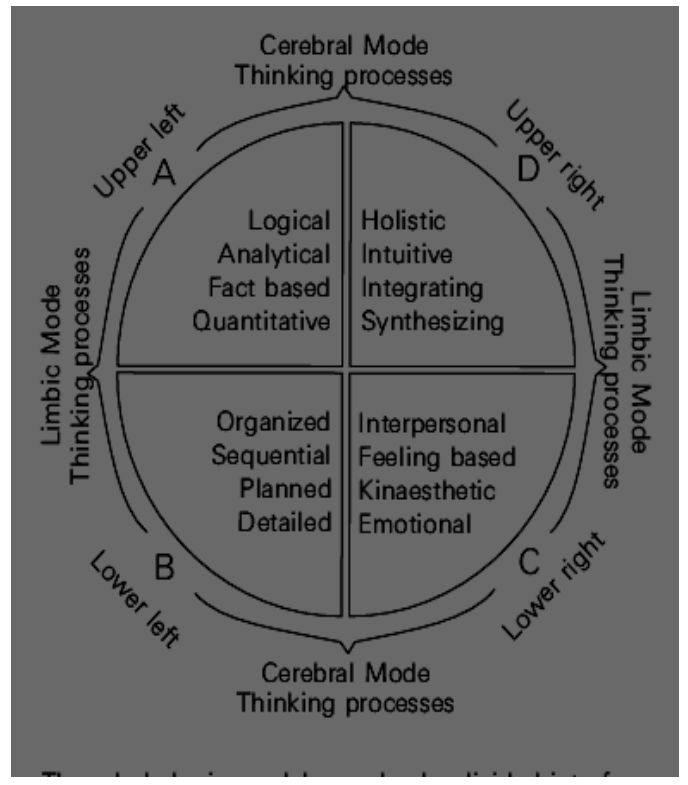

Volgens Strong (2001:15) word in die twee hemisfere van die brein verskillende tale (wêrelde) verteenwoordig. Skematies word dit in Figuur 2 voorgestel. 
Figuur 2: Skematiese voorstelling van die verskillende tale in die twee breinhemisfere (Strong, 2001:15; vgl. ook Vermeulen, 1999:110)

Linkerbrein

Regterbrein

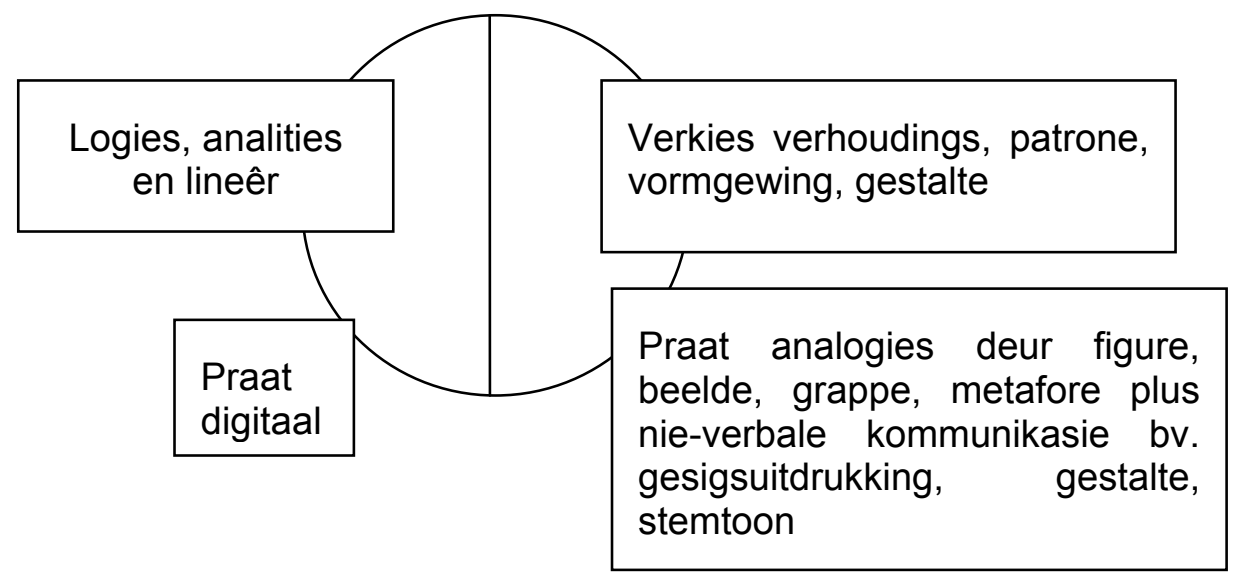

Groenewald (2003:17) wys daarop dat daar in die algemeen aanvaar is dat musiekbeoefening slegs 'n regterbreinfunksie is ( $\mathrm{vgl}$. ook Springer \& Deutsch, 1998:189). In teenstelling met bogenoemde tradisionele paradigma toon resente navorsing (Flohr et al., 2000:29; Jensen, 2000:12; Morrison, 1997:1) dat die musiekproses nie net 'n regterbreinaktiwiteit is nie, maar dat musiekbeoefening ook linkerbreinfunksies betrek (vgl. Mickela, 2000:4; Seibert et al., 2000:297; Shafer, 2000:1). Groenewald (2003:18) het in haar navorsing bevestig dat albei hemisfere by musiekprosessering betrokke is. By implikasie beteken dit dus dat musiekbeoefening 'n heelbreinfunksie is.

\subsection{Musiek en innerlike verandering}

\subsubsection{Historiese agtergrond van musiek en die mens}

Prehistories tot ongeveer 200 v.C. is relatief min oor musiek bekend. Dit is dus 'n moeilike taak om die presiese datum vir die oorsprong van musiek te bepaal. Daar kan wel histories aangevoer word dat musiek van die vroegste tye af deel uitgemaak het van die sosiale interaksies van mense (vgl. Ferreira \& Möller, 2004:31-32; De Klerk \& Smit, 2002:109; Burger, 1999:23; Pass, 1994:366). Jausovec (2006:2703) is weer van mening dat musiek eeue reeds gebruik word vir genesing en om emosies te stimuleer. Burger (1999:50) wys ook daarop dat die vermoë van musiek om mense te vermaak en emosioneel te beïnvloed reeds dekades lank erken word (vgl. ook Kayayan, 1994:347). 
Musiek begelei talle gebeurtenisse en aktiwiteite in die samelewing en is onlosmaaklik met sekere ervarings van die mens se werklikheid verweef. In die Bybelse tye is uitdrukking gegee aan emosies soos wanhoop, moedeloosheid, vreugde, dankbaarheid en rou deur middel van musiek, veral in die psalms, maar ook in ander dele in die Skrif. Gebeurtenisse soos oorloë en oorwinnings is dikwels met behulp van musiek aangekondig. (Steenkamp 2002:10; vgl. ook Maritz \& Dreyer, 2001:1277; Van Schalkwyk, 1998:14).

Nicol (1996:7) wys daarop dat musiek onlosmaaklik deel uitgemaak het van rituele, omdat dit die medium was wat die versterkende rol by die eenheid van die rituele gespeel het.

Die holistiese mens-natuurverbintenis is kenmerkend van die mens in die antieke tyd (Van Schalkwyk, 1998:15). Strukturele en funksionele afhanklikheid wat alle funksies van die sisteme in interaksie bepaal, word hierdeur aangedui. Elyon (2005:29) toon aan dat hierdie holistiese afhanklikheidsperspektief se noue verbintenis tussen musiek, spiritualisme en die godewêreld weerspieël word deur die interaksie van die mens met sang, dans en rituele. Volgens Van Schalkwyk (1998:15) het hierdie verbintenis tussen die mens en musiek egter verlore gegaan in die Westerse musiekpraktyke.

Van Schalkwyk (1998:15) tref 'n onderskeid tussen die Westerse en nie-Westerse musiektradisies. Hy meen dat musiek in die Westerse samelewing slegs ongeveer 'n duisend jaar lank beoefen word (vgl. Elliott, 1995:21). Smit (2007:258) is van mening dat musiek in die Westerse wêreld beskou word as 'n eksterne medium, iets buite die mens. Alhoewel 'n holistiese mensbeskouing aanvaar word, word die aard van musiek beskryf ooreenkomstig etiese beginsels vir dit wat as aanvaarbare (goeie) musiek of nie-aanvaarbare (slegte) musiek beskou word. Musiek word eerder volgens die funksies en waarde daarvan vir die mens gedefinieer en die invloed wat goeie of slegte musiek op die mens het (Van Schalkwyk, 1998:15).

In teenstelling met Van Schalkwyk (1998:15) is Smit (2007:258) van mening dat die Westerse musiek sy oorsprong in die Griekse en Romeinse musiektradisies gehad het. Smit (2007:258-259) wys verder daarop dat die Westerse musiek verskillende fases deurgemaak het. Die verskillende fases wat Smit (2007:258-259) onderskei, is onder andere pre-Renaissance (1300-1400), die Renaissance (1450-1600), Barok (1600-1750), die Klassieke era (1750$1800)$, die Romantiese era (1800-1900) en die Moderne era (1900 tot vandag). 
Soos hierbo aangetoon, identifiseer Van Schalkwyk (1998:16) ook nie-Westerse musiekpraktyke. In die nie-Westerse kulture verskil die soort musiek sowel as die rol wat dit in die gemeenskap vervul van die Westerse benadering. Nie-Westerse musiektradisies weerspieël die waardes, geloofsisteme, lewenswyses en mensbeskouings van die kulture en gemeenskappe waaruit dit onstaan het en beoefen word. Sterk ooreenkomste met die musiek van die pre-literêre tradisies word in die nie-Westerse musiekpraktyke waargeneem. Die musiekpraktyke van byvoorbeeld Asië, Suidoos-Asië, Arabië en die Midde- en Verre-Ooste weerspieël die belangrikheid van godsdiens, filosofie en 'n ingewikkelde mensbeskouing (vgl. Elyon, 2005:30-31).

Omdat hierdie navorsing binne die Afrikakonteks gedoen word, is dit noodsaaklik dat daar kursories verwys word na die rol van musiek binne die Afrikakultuur. As deel van kuns speel musiek volgens Smit (2007:284) en Letšosa en De Klerk (2007:71) 'n krities belangrike en onmisbare rol in die gemeenskappe van die Afrikamens (vgl. ook Maynard-Reid, 2000:69). In die Afrikakultuur word liedere gebruik om stories, reëls en waardes aan mekaar te kommunikeer. Smit (2007:284) wys verder daarop dat die Afrikamens die waarde van musiek meet aan die fisiese respons wat dit by die hoorders wek. Die effek van musiek op die intellek en emosie van die luisteraar is dus nie so belangrik binne die Afrikakultuur nie. Aangesien hierdie navorsing op die effek van musiek op die innerlike dimensie van die mens fokus en nie in die eerste plek op die sosiale effek nie, word volstaan met wat hierbo gemeld is.

\subsubsection{Invloed van musiek op die mens}

Musiek maak 'n belangrike deel uit van die mens se daaglikse bestaan (Burger, 1999:23). Verskeie navorsers het aangetoon dat die rol wat musiek in die lewe van die mens speel, onmisbaar is, omdat dit 'n verrykende funksie in die lewe van die mens vervul (vgl. Maritz \& Dreyer, 2001:1279; Janse van Rensburg, 1998:75) en ook die gedrag van mense beïnvloed (vgl. De Klerk \& Smit, 2002:109). Indien die pastorale berader/terapeut die nodige paradigmaskuif maak en musiek as 'n heelbreinaktiwiteit verwelkom, kan dit as 'n kragtige terapeutiese instrument dien, omdat musiek gelyktydig op die affektiewe, die kognitiewe en die konatiewe vlak tot die mens spreek (vgl. Begbie, 2007:20-21; Ferreira \& Möller, 2004:31; Steenkamp, 2002:10; Maritz \& Dreyer, 2001:1265; Jannasch, 1995:26).

Landre (2000:2) beklemtoon dit sterk dat musiekonderrig vir kinders onmisbaar is, omdat dit ook die kind se verstandelike vermoë ontwikkel (vgl. ook Campbell, 2000:8, 15; Jensen, 2000:30-36; Lehr, 
1998:40). Groenewald (2003:47) sluit daarby aan wanneer sy skryf dat musiekbeoefening kinders se akademiese prestasie verbeter na 'n tydperk van musiekbeoefening (vgl. ook Jausovec, 2006:2703; Ferreira \& Möller, 2004:32).

Spies en Groenewald (2005:415) is van mening dat musiek die mens nie net kognitief beïnvloed nie, maar dat kreatiewe vermoëns, deursettingsvermoë, noukeurigheid, positiewe selfbeeld, waagmoed, selfdissipline, selfanalise en verdraagsaamheid ook eienskappe is wat musiekbeoefening by musiekleerders bevorder (vgl. ook Makarov, 1997:1-2).

Musiek word veelal erken as die taal van die heelal, omdat dit mense van alle rasse en kulture bymekaar bring (Elyon, 2005:27; vgl. ook Seibert et al., 2000:296; Jensen, 2000:21; Van Schalkwyk, 1998:2; Nicol, 1996:6). Steenkamp (2002:12) wys daarop dat die mens ontologies en epistemologies aan musiek verbind is. Dit impliseer dat die terapeutiese funksie in musiek in pastorale berading/ terapie vanuit 'n geloofsperspektief aangewend kan word.

Musiek help om die mens nader aan die wese van sy emosies te bring (Elyon, 2005:39; vgl. ook Ferreira \& Möller, 2004:31). Wanneer 'n persoon byvoorbeeld emosioneel en tranerig voel, sal musiek wat trane prikkel, dit aanhelp. Wanneer dieselfde persoon op 'n ander geleentheid in 'n ander stemming na dieselfde musiek luister, sal dit moontlik 'n ander emosie tot gevolg hê. Die krag van musiek bestaan daarin dat dit eg kan wees aan die "lewe van gevoelens" (vgl. Jausovec, 2006:2703; Baumgartner et al., 2006:40). Lai (1999: 230) wys daarop dat musiek nie alleen die emosies van die mens beïnvloed nie, maar ook 'n buitengewone uitwerking het op die fisiologiese toestand van die mens (vgl. Jensen, 2000:17-18).

Die mees algemene terapeutiese gebruik van musiek is vir ontspanning en die vermindering van spanning (stres). Dit kan onder andere ook help om diepgewortelde emosies na die oppervlak te bring, omdat musiek die emosies van die mens aanraak (Campbell, 1997: 162).

Spies en Groenewald (2005:419) is van mening dat musiekbeoefening die beginpunt is om die innerlike wêreld van die mens se hart te betree. 'n Ander faset word na vore gebring deur Ferreira en Möller (2004:32) wat daarop wys dat terapeutiese aanwending van musiek help met die oplossing van innerlike konflik en 'n positiewe verandering in emosionele ervarings en gedrag bevorder. 
In 'n kwalitatiewe empiriese ondersoek ten einde vas te stel watter effek heelbreinaktiwiteit met betrekking tot die innerlike verandering op sewe deelnemers het, het Elyon (2008) die volgende resultate bereik - wat met bogenoemde navorsing korreleer, dit bevestig en versterk. Die navorsingsresultate het geldig aangedui dat musiek as heelbreinaktiwiteit gebruik kan word om innerlike verandering teweeg te bring:

- Musiek het 'n definitiewe uitwerking op die gemoedstoestand van die mens. Die effek van musiek op die gemoedstoestand van die mens kan negatief of positief wees.

- Sekere musiek soos lofprysings- en aanbiddingsmusiek vervul 'n opbouende, versterkende, ondersteunende, vervullende en komplementerende rol by die geloofservaring van die mens.

- Musiek kan ook 'n didaktiese funksie vervul.

- Lofprysings- en aanbiddingsmusiek kan ook geestelike groei by die mens bevorder.

- Deur musiek kan groei by verhoudings, interaksie met ander, wysheid en musieksmaak ook plaasvind.

- Musiek help die mens om in tye van krisis sy toevlug tot God te neem.

- Lofprysings- en aanbiddingsmusiek help die mens in moeilike tye om sy fokus vanaf die probleem na God te verskuif.

- Musiek is 'n uitstekende medium vir die mens om uitdrukking aan emosies te gee.

- Musiek maak diepgewortelde emosies los en skep 'n geleentheid vir die Heilige Gees om die mens met vergifnis te bedien.

- Musiek bring ook innerlike vrede en rustigheid in die lewe van die mens.

\section{Gevolgtrekkings}

In die navorsing is dit bevestig dat verandering 'n doelwit is van alle berading/terapie. Voordat enige verandering ' $n$ aanvang kan neem en gefasiliteer kan word, is dit van kardinale belang dat die individu moet erken dat regstelling of aanpassing in sy/haar lewe nodig is. Verandering van mense se oortuigings is moontlik, maar is ' $n$ uiters moeilike taak en verg harde werk en deursettingsvermoë. 
Volgens Rogers se perspektief maak verandering inherent deel uit van menslike ervaring. Die berader/terapeut sal daarom nie die inisieerder van verandering wees nie, maar slegs die veranderingsproses in die lewe van die kliënt fasiliteer.

Om musiek as heelbreinaktiwiteit te ondersoek, was dit nodig om ook die funksies van die brein te bestudeer. Aangesien die navorsing van die brein 'n gespesialiseerde veld op sy eie is, is die ondersoek na die breinfunksies in hierdie artikel bloot inleidend van aard en is hoofsaaklik gefokus op dit wat op musiek betrekking het. Dit is algemeen aanvaar dat musiek slegs 'n regterbreinaktiwiteit is, maar resente bronne het egter getoon dat musiekprosesse ook linkerbreinfunksies betrek. Dit impliseer dus dat musiekbeoefening en musiekbeluistering 'n heelbreinfunksie is.

Histories kan aangevoer word dat musiek sedert die vroegste tye reeds ' $n$ integraal-belangrike rol in die lewe van die mens vervul het. Die vermoë van musiek om die mens te vermaak en emosioneel te beïnvloed, word dekades lank reeds erken. Omdat musiek talle gebeurtenisse en aktiwiteite in die samelewing van die mens begelei en gelyktydig op die affektiewe, die kognitiewe en die konatiewe vlak tot die mens spreek, kan dit nie losgemaak word van sekere ervarings van die mens se werklikheid nie.

In hierdie artikel het dit verder na vore gekom dat musiekonderrig vir kinders van kardinale belang is, omdat dit die kind se verstandelike vermoë ontwikkel asook sy/haar akademiese prestasie verbeter. Musiek beïnvloed die mens nie alleen kognitief nie, maar bevorder ook sy/haar algehele ontwikkeling. Ander navorsers het waargeneem dat interpersoonlike vaardighede bevorder word wanneer leerders musiek in groepsverband beoefen. Sensitiwiteit vir ander se emosies, empatie en meelewing (as basiese komponente van emosionele intelligensie) is by leerders wat musiek in groepsverband beoefen, opgemerk. Die mees algemeen erkende terapeutiese aanwending van musiek is vir die ontlading van spanning (stres) en vir ontspanning en die rol wat dit speel met betrekking tot die emosies van die mens wat geraak word.

Die mens bevind homself in die postmoderne era. Die eis van die tyd waarin ons leef, is dat die mens ' $n$ dringende behoefte het na geïntegreerdheid en heelheid. Multidimensionele denke, gevoelens en ervarings is 'n gevolg van die paradigmaskuif wat 'n uitvloeisel van die postmodernisme was. Die paradigmaskuif beklemtoon die invloed van waardes, simbole, rituele, metafore en die kunste. Volgens die bevindings van navorsing wat in hierdie artikel vervat is 
(wat ook 'n empiriese ondersoek insluit), is innerlike verandering en heelwording van die postmoderne mens moontlik deur die gebruik van musiek.

As heelbreinaktiwiteit kan en behoort musiek derhalwe gebruik te word om innerlike verandering teweeg te bring.

\section{Geraadpleegde bronne}

ANDREAS, S. \& FAULKNER, C. 1998. NLP: The new technology of achievement. London: Nicolas Brealey.

BAUMGARTNER, T., ESSLEN, M. \& JÄNCKE, L. 2006. From emotion to perception to emotion experience: emotions evoked by pictures and classical music. International journal of psychophysiology, 60:34-43.

BEGBIE, J. 2007. Sound theology: meaning in music. The Christian century, 124(23):20-25.

BERTRAM, P.K. \& WIDENER, A.J. 1995. Psychodynamic therapies in historical perspective. (In Bongar, B. \& Beutler, L.E., eds. Comprehensive textbook of psychotherapy: theory and practice. New York: Oxford University Press. p. 24-47.)

BURGER, S. 1999. Die effek van 'n gestruktureerde oudiopsigofonologiese program met musikale jong volwassenes. Potchefstroom: $\mathrm{PU}$ vir $\mathrm{CHO}$. (M.A.-verhandeling.)

CAHOONE, L. 2003. From modernism to postmodernism: an anthology. Oxford: Blackwell.

CAMPBELL, D.G. 1997. The Mozart effect: tapping the power of music to heal the body, strengthen the mind and unlock the creative spirit. New York: Hodder \& Stoughton.

CAMPBELL, D.G. 2000. The Mozart effect for children. London: Hodder \& Stoughton.

CAMPBELL-LANE, Y. 2003. Inner change: a pastoral-theological study. Potchefstroom: North-West University. (Ph.D.-proefskrif.)

CILLIERS, J. 1998. Die uitwysing van God op die kansel. Kaapstad: Lux Verbi.

CLINEBELL, H. 1984. Basic types of pastoral care \& counselling. Nashville: Abingdon Press.

COREY, G. 2001. Theory and practice of counseling and psychotherapy. Pacific Grove: Brooks/Cole.

D'AQUILI, E. \& NEWBERG, A.B. 1999. The mystical mind: probing the biology of religious experience. Minneapolis: Fortress.

DE BOER, A.L., STEYN, T. \& DU TOIT, P.H. 2001. A whole brain approach to teaching and learning in higher education. South African journal for higher education/Suid-Afrikaanse tydskrif vir hoër onderwys, 15(3):185-193.

DE KLERK, B.J. \& SMIT, E.J. 2002. Pneuma en nous in die gereformeerde kerklied: perspektiewe uit 1 Korintiërs 14:15 en die tradisie, toegespits op die musiek en poësie van die kerklied. In die Skriflig, 36(1):105-124.

DILL, J. \& KOTZÉ, D.J. 1997. Verkenning van 'n posmoderne epistemologiese konteks vir die praktiese teologie. Acta theologica, 17(1):1-26.

DIXON, C. 1998. Sexual revictimization in "coloured" female survivors of child sexual abuse: an integrated approach. Johannesburg: RAU. (M.A. dissertation.) 
DREYER, Y. 1998. Pastorale interaksie met vroue: 'n prakties-teoretiese begronding. Pretoria: Universiteit van Pretoria. (D.D.-thesis.)

DU TOIT, P.W. \& SPANGENBERG, I.J.J. 2002. Kerk en teologie in die postmoderne tyd. Hervormde teologiese studies, 58(3):1134-1153.

ELLIOTT, D.J. 1995. Music matters. New York: Oxford University Press.

ELLIS, A. 1990. The issue of force and energy in behavioral change. (In Dryden, W. \& Diguiseppe, R., eds. A primer on rational-emotive therapy. Champaign: Research Press. p. 137-286.)

ELYON, J.R. 2005. Pastoral music therapy with a grieving child because of the death of a parent. Bloemfontein: University of the Free State. (M.A. dissertation.)

ELYON, J.R. 2008. Die rol van musiek as heelbrein-strategie by innerlike verandering: 'n prakties-teologiese studie. Potchefstroom: NoordwesUniversiteit. (Ph.D.-proefskrif.)

ENGLER, B. 1991. Personality theories: an introduction. Princeton: Houghton Mifflin.

FERREIRA, R. \& MÖLLER, L. 2004. Musiekterapie as intervensie-moontlikheid by laerskooldogters wat seksueel misbruik is. Child abuse research in South Africa, 5(2):31-40.

FLOHR, J.W., MILLER, D.C. \& DEBEUS, R. 2000. EEG research with young children. Music education journal, 87(2):28-32.

GROENEWALD, M. 2003. Die verband tussen musiekbeoefening en intelligensie. Potchefstroom: PU vir CHO. (Ph.D.-proefskrif.)

HERRMANN, N. 1995. The creative brain. Lake Lure: Brain Books.

HERRMANN, N. 1996. The whole brain business book. New York: McGraw Hill.

HERRMANN, N. 1998. Twenty years of thinking about the thinking brain: a special summary of learning outcomes. (Unpublished document.)

JACOB, R.G. \& PELHAM, W.E. 2005. Behavior therapy. (In Sadock, B.J. \& Sadock, V.A., ed. Kaplan \& Sadock's comprehensive textbook of psychiatry. 2 vols. New York: Lippincott Williams \& Wilkins. p. 2498-2548.)

JAFFE, D.T. \& SCOTT, C.D. 1999. Getting your organization to change. Menlo Park: Crisp Publications.

JANNASCH, T. 1995. Musiek as hulpmiddel in spelterapie. Pretoria: Universiteit van Pretoria. (M.A.-verhandeling.)

JANSE VAN RENSBURG, J. 1998. Regterbrein-strategieë vir pastorale terapie. Nederduitse Gereformeerde teologiese tydskrif, 39(1 \& 2):65-78.

JANSE VAN RENSBURG, J. 2000. Paradigm shift. Pretoria: Van Schaik.

JAUSOVEC, N., JAUSOVEC, K. \& GERLIC, I. 2006. The influence of Mozart's music on brain activity in the process of learning. Clinical neurophysiology, 117:2703-2714.

JENSEN, E. 2000. Music with the brain in mind. San Diego: The Brain Store.

KARASU, T.B. 2005. Psychotherapies: psychoanalysis and psychoanalytic psychotherapy. (In Sadock, B.J. \& Sadock, V.A., ed. Kaplan \& Sadock's comprehensive textbook of psychiatry. 2 vols. New York: Lippincott Williams \& Wilkins. p. 2472-2498.)

KAYAYAN. E. 1994. Skylight on music. (In Venster op die kunste: Christelike perspektief. Potchefstroom: PU vir CHO. p 346-362.)

KINGMA, B.R. \& LOTTER, G.A. 2002. Begrip vir die lewenskonteks van mense as 'n vereiste vir pastorale begeleiding. Koers, 67(3):309-328. 
KOTZÉ, E. \& KOTZÉ, D.J. 1997. Social construction as a postmodern discourse: an epistemology for conversational therapeutic practice. Acta theologica, 17(1):27-50.

LACCINO, J.F. 1993. Left brain-right brain differences: inquiries, evidence and new approaches. New Jersey: Lawrence Erlbaum Associates.

LAI, Y. 1999. Effects of music listening on depressed women in Taiwan. Issues in mental health nursing, 20(3):229-246.

LANDRE, N. 2000. Can music make your child smart? Music study may help train the brain for higher forms of thinking. http://family.go.com/ PrinterFriendly/ Date of access: 31 Jul. 2007.

LEHR, M.R. 1998. Music education: the brain-building subject. Teaching music, 6(3):40-56.

LETŠOSA, R.S. \& DE KLERK, B.J. 2007. A relevant liturgy for reformed churches of African origin concerning liturgical music. Praktiese teologie in Suid-Afrika, 22(1):64-82.

LOUW, D.J. 2000. A pastoral hermeneutics of care and encounter: a theological design for a basic theory, anthropology, method and therapy. Wellington: Lux Verbi.

MACASKILL, N.D. 1990. Educating clients about rational-emotive therapy. (In Dryden, W. \& Diguiseppe, R., eds. A primer on rational-emotive therapy. Champaign: Research Press. p. 42-60.)

MAKAROV, V. 1997. A piano teaching method for children of early ages. Translated by Phillip Shovk. Sydney: Third Australian National Piano Pedagogy Conference, 1994.

MARITZ, J.F. \& DREYER, T.F.J. 2001. Musiek as hulpmiddel in pastorale terapie. Hervormde teologiese studies, 57(3 \& 4):1265-1287.

MAYNARD-REID, P.U. 2000. Diverse worship: African-American, Carribean and Hispanic perspectives. Downers Grove: InterVarsity.

McLEOD, J. 1996. The humanistic paradigm. (In Woolfe, R. \& Dryden, W., eds. Handbook of counseling psychology. London: Sage. p. 133-155.)

MICKELA, T. 2000. Music lessons may open the mind to math and sciences: music and the brain. http://pionet.net/ hub7/music.html Date of access: 31 Jul. 2000.

MORRISON, B. 1997. UC Irvine study shows that exposure to music enhances early childhood development of brain. http://www.communications. uci.edu/releases/026wb97.html Date of access: 31 Jul. 2007.

NEETHLING, K. \& RUTHERFORD, R. 2001. Creative people can perform miracles. Vanderbijlpark: Carpe Diem.

NICOL, A. 1996. Musiek as deel van 'n ko-kreatiewe proses. Pretoria: Unisa. (M.A.-skripsie.)

OLTHUIS, J.H. 1999. Dancing together in the wild spaces of love: postmodernism, psychotherapy and the spirit of God. Journal of psychology and Christianity, 8(2):140-152.

PASS, D.B. 1994. Christian perspectives on the arts: the case of music. (In Venster op die kunste: Christelike perspektiewe. Potchefstroom: PU vir CHO. p 363-381.)

PETERSON, C. 2006. A primer in positive psychology. New York: Oxford University Press.

RENNIE, D.L. 1998. Person-centered counseling: an experiencial approach. London: Sage. 
SCHMIDT, W.H. 1997. Reflections on groups and OD. Organization development journal, 18(2):87-90.

SEIBERT, P.S., FEE, L., BASOM, J. \& ZIMMERMAN, C. 2000. Music and the brain: the impact of music on an oboist's fight for recovery. Brain injury, 14(3):295-302.

SHAFER, A. 2000. Research shows correlation between music and language meganisms. http://www.menc.org/information/advocate/brain.html Date of access: 31 Jul. 2007.

SMIT, E.J. 2007. Die bydrae van die gereformeerde kerklied tot versoening en eenheid in 'n multikulturele Suid-Afrika. Potchefstroom: NoordwesUniversiteit. (Ph.D.-proefskrif.)

SMITH, D.L. 1996. Psychodynamic therapy: the Freudian approach. (In Dryden, W., ed. Handbook of individual therapy. London: Sage. p.19-39.)

SMITH, J.K.A. 2006. Who's afraid of postmodernism? Grand Rapids: Baker Academic.

SPIES, B.M. \& GROENEWALD, M. 2005. Musiek in diens van menslike kapasiteitsbou. Tydskrif vir geesteswetenskappe, 45(3):412-421.

SPRINGER, S.P. \& DEUTSCH, G. 1998. Left brain, right brain. New York: Freeman.

STEENKAMP, E.P. 2002. Die waarde van musiek as ritueel in narratiewe berading. Potchefstroom: PU vir CHO. (M.A.-verhandeling.)

STEENKAMP, L.J.S. 1996. Kerk en kultuur in 'n postmoderne samelewing. Hervormde teologiese studies, 52:746-764.

STEYN, R.S. 2005. Die impak van die postmodernisme op voorhuwelikse verhoudings: 'n pastorale navorsing. Potchefstroom: NoordwesUniversiteit. (Ph.D.-proefskrif.)

STRAUSS, D.F.M. 2004. How "postmodern" is "postmodernism"? Koers, 69(2):259-276.

STRONG, P. 2001. Die gebruik van filmterapie in pastorale berading. Potchefstroom: PU vir CHO. (M.A.-verhandeling.)

THOMPSON, D. 1999. Postmodernism. Athens: University of Georgia Press.

THOMPSON, G.G. \& LOTTER, G.A. 2001.Challenges and opportunities of postmodernity for the church. Studia historiae ecclesiasticae, 27(1):184216

THORNE, B. 1996. Person-centered therapy. (In Dryden, W., ed. Handbook of individual therapy. London: Sage. p. 121-146.)

VAN DER WALT, B.J. 2006. Die postmodernisme: 'n verleentheid en 'n geleentheid. Die Kerkblad, 32-34.

VAN HUYSTEEN, J.V.W. 1996. The shaping of rationality in science and religion. Hervormde teologiese studies, 52:105-129.

VAN SCHALKWYK, C. 1998. Die gebruik van musiek in opvoedkundigesielkundige terapie. Pretoria: Unisa. (M. Ed.-verhandeling.)

VAN SCHALKWYK, G.J. 1998. 'n Sisteemparadigma vir musieksielkunde. Pretoria: Universiteit van Pretoria. (Ph.D.-proefskrif.)

VAN WYK, J.H. 2001. Fokus: geloof en wete(-nskap): in gesprek met Ben du Toit. In die Skriflig, 35(1):141-146.

VERMEULEN, P.J. 1999. Pastorale dimensies van sekere gelykenisse in die Ou Testament. Potchefstroom: PU vir CHO. (Ph.D.-proefskrif.)

VOGES, A. 1999. Die rol van linker- en regterbreinintegrasie by kreatiewe denkontwikkeling. Pretoria: Unisa. (M.Ed.-verhandeling.) 
WELCH, I.D. 1998. The path of psychotherapy: matters of the heart. Pacific Grove: Brooks/Cole.

WELCH, J. \& WELCH, S. 2005. Winning. London: Harper Collins.

WEST, A. \& SAUNDERS, S. 2006. A humanistic approach to South African accounting education. South African journal for higher education/SuidAfrikaanse tydskrif vir hoër onderwys, 20(5):718-732.

WILSON, D.N. 2006. Postmodern epistemology and the Christian apologetics of C.S. Lewis. Verbum et ecclesia, 27(2):749-771.

WILSON, F.R. 2000. Music improves reasoning in pre-school children. http://pionet.net hub7/pre.html Date of access: 19 Jun. 2001.

WILSON-DICKSON, A. 1997. A brief history of Christian music. Oxford: Lion.

WOLITZKY, D.C. 1995. Traditional psychoanalytic psychotherapy. (In Gurman, A.S. \& Messer, S.B., eds. Essential psychotherapies: theory and practice. New York: Guilford. p. 12-54)

YATES, M.P. 2003. Rational emotive behavioural therapy and Christian belief. Potchefstroom: PU for CHE. (Ph.D.-thesis.)

\section{Kernbegrippe:}

heelbreinaktiwiteite

innerlike verandering

musiekterapie

Key concepts:

inner change

music therapy

wholebrain activity 